\title{
Quantitative Compositional Mapping of Core-Shell Polymer Microspheres by Soft X-ray Spectromicroscopy
}

\section{Koprinarov, A. P. Hitchcock,* W. H. Li, Y. M. Heng, ‘ and H. D. H. Stöver}

Department of Chemistry \& BIMR, McMaster University, Hamilton, Ontario L8S 4M1, Canada

Received September 20, 2000; Revised Manuscript Received March 14, 2001

\begin{abstract}
Core-shell polymer microspheres have been prepared by a two-step precipitation polymerization. These mi crospheres consist of $3.2 \mu \mathrm{m}$ polydivinyl benzene 55 (DVB 55) cores coated with $\sim 0.4-0.9$ $\mu \mathrm{m}$ wide shells composed of poly(DVB55-co-E DMA), a random copolymer of DVB55 and ethylene glycol dimethyl acrylate (EDMA). The chemical composition, core-shell morphology, and porosity of these structured microspheres have been studied quantitatively with scanning transmission X-ray microscopy (STXM) at a spatial resolution of $100 \mathrm{~nm}$. I mages recorded at selected energies through the $C$ is absorption region were analyzed using singular value decomposition to obtain quantitative maps of the DVB55 and EDMA components. The EDMA concentration in the shell determined by STXM was found to be in good agreement with that predicted from the comonomer composition over the range of $10-90 \%$ EDMA. The precision of chemical quantification at high spatial resolution is shown to be adequate for STXM to be useful in guiding the development of structured polymeric systems for particular applications.
\end{abstract}

\section{Introduction}

Many structural and functional polymers currently devel oped are based on nanoscale composites. Examples include liquid crystal display matrices containing dispersed phases that respond to applied electric fields, ${ }^{1}$ structural epoxy thermoset blends, ${ }^{2}$ and polyester resins formed by polymerization-induced phase separation (PIPS) $^{3}$ as well as polymer composites formed by annealing blends of two or more preformed polymers. Polymer microspheres and microcapsules with tailored internal structures are attractive for a wide number of applications, including stationary phases for separation science, ${ }^{4,5}$ biomedical devices, ${ }^{6}$ coating additives, ${ }^{7}$ and controlled release reservoirs. ${ }^{8,9}$ Particular morphologies desired for different applications include internal porosity ${ }^{10}$ and core-shell structures. ${ }^{11,12}$

To optimize the internal or core-shell morphologies of such composite materials for particular applications, such as controlled release capsules ${ }^{13-15}$ or chromatographic separations, ${ }^{16}$ one needs, first, to visual ize the internal structure at high spatial resolution and, second, to perform quantitative chemical analysis at the spatial scale of that structure. Traditional chemical spectroscopies used for polymer studies, such as infrared and nuclear magnetic resonance, can easily differentiate chemical species but do not have the necessary submicron spatial resolution. Analytical transmission and scanning transmission electron microscopes ((S)TEM) have excellent spatial resolution and are very useful to visualize submicron structures, but electron microscopy typically does not offer sufficient chemical sensitivity for quantitative chemical mapping beyond the elemental level. Indeed, one cannot always be sure whether features observed by electron (or optical) microscopy arise from chemical inhomogeneity or simply from density or thickness variations of the specimen. Selective staining can be used to increase the chemical

\footnotetext{
† Current address: Princess Margaret Hospital, University of Toronto.

* To whom correspondence should be addressed. E-mail aph@ momaster.ca.
}

sensitivity, but this remains an indirect method, one which may lead to artifacts. Furthermore, high-resolution electron microscopy of polymers is experimentally difficult on account of the radiation damage caused by the high-energy electron beams. ${ }^{17-19}$

Recently, analytical soft X-ray microscopy has been developed and applied to study polymers. ${ }^{20-23}$ The scanning transmission X-ray microscope (STXM ) ${ }^{24-27}$ at the Advanced Light Source (ALS) used in this work provides images with better than $100 \mathrm{~nm}$ spatial resolution and a photon energy resolution of about $100 \mathrm{meV}$. Near-edge X-ray absorption fine structure (NEXAFS) spectral signals ${ }^{28}$ are the basis for chemical speciation. By chemical speciation we mean the quantitative mapping of specific chemical compounds from fine details of the NEXAFS spectra, as opposed to el emental mapping, as can be obtained from X-ray fluorescence analysis or other techniques. Here we have used carbon is spectroscopy, but other core edges, particularly $\mathrm{N}$ 1s and $\mathrm{O}$ 1s, can also be very useful. The photon flux transmitted through a column of the sample is related to the amount of each compound present, with a weighting given by the mass absorption coefficient of that compound at the photon energy employed. Since NEXAFS spectra for pure materials can be easily converted to accurate mass absorption scales, STXM can be used for quantification at submicron scales. ${ }^{29}$ While radiation damage is still a concern, for equivalent spatially resolved analysis, it has been shown to be about 2 orders of magnitude lower in STXM than in analytical electron microscopy. ${ }^{30}$

The present paper reports a study of the chemical composition of the $400-900 \mathrm{~nm}$ wide shell region of a particular family of microspheres, carried out to investigate the precision of STXM quantification. This information is needed in order to evaluate the types of problems in polymer physics and chemistry to which STXM polymer microanalysis will be applicable. From the results obtained here it is clear that STXM can provide reliable chemical speciation at sub-100 nm spatial resolution of majority components ( $>5 \%)$. This capability will be useful in areas such as phase segrega- 
tion, morphology, and interface chemistry of blends and copolymer systems prepared by polymerization-induced phase separation, colloidal self-assembly, 31,32 and other methods.

\section{Experimental Section}

2.1. Sample Preparation. The core-shell microspheres were prepared by a two-step precipitation polymerization as described previously. ${ }^{11}$ First, $10 \mathrm{~mL}(0.919 \mathrm{~g})$ of DVB55 and $0.182 \mathrm{~g}$ of azobis(isobutyronitrile) (AIBN) were dissolved in $500 \mathrm{~mL}$ of acetonitrile, placed in a polypropylene screw-cap bottle, and rotated on a set of horizontal stainless steel rollers at $70{ }^{\circ} \mathrm{C}$ for $24 \mathrm{~h}$. The resulting poly(DVB55) core particles were isolated by filtration, washed in sequence with tetrahydrofuran, acetone, and methanol, and dried. About $100 \mathrm{mg}$ each of these core partides was placed into polypropylene vials and resuspended in $30 \mathrm{~mL}$ of acetonitrile containing $0.3 \mathrm{~mL}$ of a mixture of DVB55 and EDMA and $0.003 \mathrm{~g}$ of AIBN. Rotation at $70{ }^{\circ} \mathrm{C}$ for another $24 \mathrm{~h}$ gave the core-shell particles, having poly(DVB55-co-EDMA) copolymer shells ranging in thickness from 400 to $900 \mathrm{~nm}$, with EDMA contents from 10 to $100 \%{ }^{11}$

The core-shell microspheres were embedded in Spurr formula epoxy resin, cured, and ultramicrotomed to form sections between 50 and $100 \mathrm{~nm}$ thick. Spurr epoxy resin is a very common embedding resin used in electron microscopy. It is a relatively nonviscous mixture of nonenyl succinnic anhydride, vinylcyclohexene dioxide, diglycidyl ether of polypropylene glycol (plasticizer), and 2-(dimethylamino)ethanol (curing agent). Curing is carried out at el evated temperature, and stopped short of full cross-linking, to prevent the specimen from becoming too brittle. As a result, conversion is less than complete, and it is possiblethat some portion of residual liquid resin is drawn across the face of the microspheres during microtoming. As well, during specimen preparation, some of the lower molecular weight components of the resin may be able to diffuse into any pores present in the core-shell particles.

2.2. Characterization of Core-Shell Microspheres. During shell formation, EDMA and DVB55 are expected to copolymerize nearly randomly, with a slight preference toward alternating sequence, given that the reactivity ratios for styrene and methyl methacrylate, a close mimic for EDMA, are approximately 0.5 and $0.45 .{ }^{33}$ Conversion of the two comonomers during shell formation increases from $12 \%$ to $57 \%$ on going from $10 \%$ to $90 \%$ EDMA. This low conversion is due to the low total monomer loading in this second step of $1 \%$. It helps ensure that the copolymer composition in the shell does not deviate too far from the comonomer feed ratio.

TEM images of the resulting microtome sections revealed the expected core-shell structure.11 Figure la shows an example of a TEM image of monodisperse core-shell microspheres prepared with an EDMA content in the shell of 30 vol \%. The overall core-shell morphology is clearly visible due to the different electron densities of core and shell polymer. Not clear from such TEM images is the exact composition of the shell and whether the apparent contrast between core and shell is in part due to the presence of porosity in either core or shell. $34-36$

2.3. Scanning Transmission X-ray Microscopy (STXM) Measurements. $C$ 1s images were recorded with beam line 7.0 STXM at the Advanced Light Source (ALS). ${ }^{27}$ Theimaging is performed in helium atmosphere established in the microscope once the sample is installed. The transmitted photon flux is measured with single photon counting using a phosphor converter ( $\left.\mathrm{P} 43, \mathrm{GdO}_{2} \mathrm{~S}_{2}: \mathrm{Tb}\right)$ and a high-performance photomultiplier tube (Hamamatsu 647P). This system is linear up to about $40 \mathrm{MHz}$ when using a divide-by-10 amplifier to avoid nonlinearity in the pulse processing. Typical count rates are about $2 \times 10^{7}$ photons/s transmitted through the helium at $300 \mathrm{eV}$, with the ALS storage ring running at $1.9 \mathrm{eV}$ and 400 $\mathrm{mA}$. Typically, counting periods (dwell times) of $0.2 \mathrm{~ms}$ per pixel were used for imaging. The spatial resolution of the microscope is about $100 \mathrm{~nm}$, mainly due to mechanical

\section{(a) TEM}

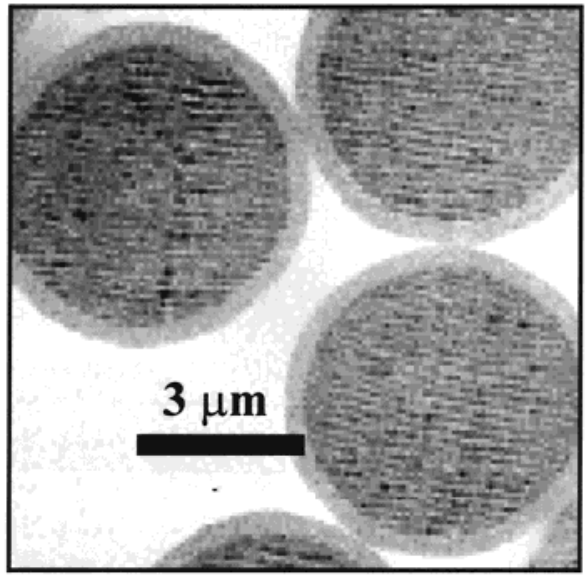

(b) STXM $\mathbf{5} \mu \mathbf{m}$

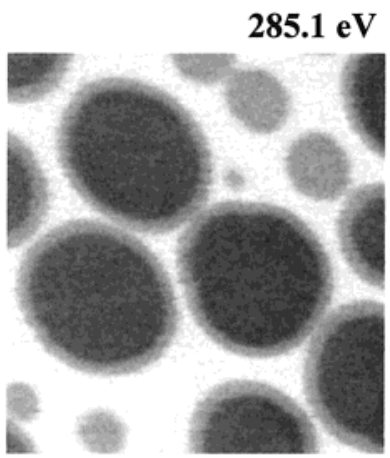

$288.5 \mathrm{eV}$

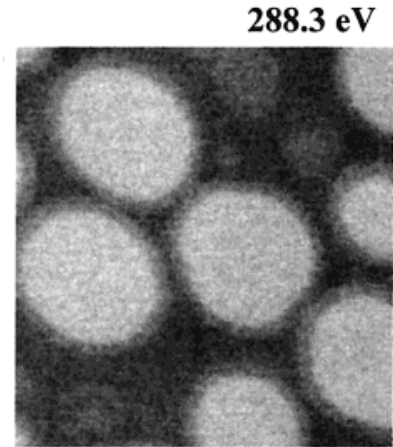

$305.1 \mathrm{eV}$
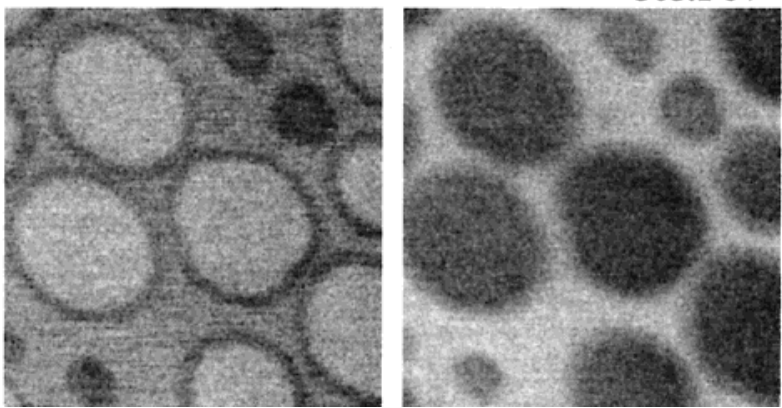

Figure 1. (a) A bright field electron micrograph of microspheres composed of a core of pure poly(DVB55) and a shell of poly(DVB55-co-EDMA with 70\% (v/V) DVB55. The microspheres were embedded in Spurr's epoxy and microtomed. (b) STXM images at 285.1, 288.3, 288.5, and $305.1 \mathrm{eV}$ of the microspheres containing 70\% (v/v) EDMA and $30 \%(\mathrm{v} / \mathrm{v})$ DVB55 in the shell and 100\% DVB55 in the core. Although the epoxy is spectrally similar to EDMA, a $0.2 \mathrm{eV}$ energy change near the strong $\pi^{*} \mathrm{C}=\mathrm{O}$ peak readily distinguishes shell and epoxy. The small $285 \mathrm{eV}$ signal in the EDMA spectrum, although unexpected from the structure, was found in all measurements and may be from an impurity.

vibration limitations, rather than the zone plate, which has a diffraction limited resolution of $\sim 50 \mathrm{~nm}$. The monochromator slits were set to achieve an energy resolution of about $100 \mathrm{meV}$ in the carbon 1s region $(\mathrm{E} / \Delta \mathrm{E} \sim 3000)$.

I mages were recorded at selected energies through the $C$ 1 s region (280-320 eV). Postacquisition image alignment was necessary to correct for drift of the field of view on account of lateral run-out of the zone plate during movement of the zone plate along the optical axis to maintain focus for different photon energies (wavelengths) throughout the scan. The methodol ogy and first generation analysis software for image sequence ("stack") acquisition and analysis were devel oped by Chris J acobsen. ${ }^{37}$ After each image sequence measurement, 
an image was recorded at a photon energy sensitive to radiation damage $(288 \mathrm{eV})$ in order to confirm that the total X-ray dose was below that producing detectable damage.

Reference spectra of the pure polymeric components were recorded with the same instrument. For DVB55, spectra of 100\% DVB55 particles embedded in Spurr resin were used. For EDMA, the spectrum was acquired from a neat poly(EDMA) mi crogel film. The spectra ware calibrated by setting the maximum of the strong $\pi^{*}{ }_{C=C}$ of poly(DVB55) to $285.1 \mathrm{eV}$. The incident flux, measured before or after each series of images, was used to convert the images to optical density. ${ }^{29}$

\section{Results and Discussion}

3.1. Quantitation of Shell Composition. A bright field transmission electron micrograph, presented in Figure 1a, shows the structure of poly(DVB55-EDMA) core-shell microspheres containing 70 vol \% DVB55 and 30 vol \% EDMA in the shell, embedded in epoxy. The dark $3.2 \mu \mathrm{m}$ core of poly(DVB55) is surrounded by a lighter $\sim 300 \mathrm{~nm}$ thick shell of poly(DVB55-co-EDMA). The horizontal lines visible in the core section are microtoming artifacts, reflecting the near vertical travel direction of the microtome diamond knife through the brittle DVB55 cores. Figure $1 \mathrm{~b}$ shows, as an example, STXM images at 285.1, 288.3, 288.5, and $305.1 \mathrm{eV}$ of microspheres having the same composition with $70 \%$ (v/ v) EDMA and $30 \%(\mathrm{v} / \mathrm{v})$ DVB55 in the shell. The microtome sections of the microspheres are circular, but the STXM images are distorted by Abbe errors in the sample scanning system. While this can be readily removed by software manipulation of images, we prefer to present the data without this transformation. A new scanning system is being implemented in the next generation of STXM at the ALS which will eliminate these distortions.

Three steps of contrast reversal can be observed upon varying the photon energy which reflect the sensitivity to the three chemical components. The spectroscopic basis for distinguishing these components is presented in Figure 2, which shows the C 1s NEXAFS spectra of Spurr epoxy resin, poly(DVB55) and poly(EDMA), along with assignments for the principal features. The epoxy and the EDMA spectra are dominated by $\mathrm{C} 1 \mathrm{~s}(\mathrm{C}=\mathrm{O}) \rightarrow$ $\pi^{*}{ }_{C=0}$ transitions at $288.3 \mathrm{eV}$. There is a $\sim 0.2 \mathrm{eV}$ energy shift between the $\pi^{*} C=0$ resonances of the epoxy and EDMA which provides the potential to distinguish these components. At photon energies different than 288.0$288.4 \mathrm{eV}$, these two components are very difficult to distinguish, which is why the shell is difficult to visualize except at very car efully selected energies. The DVB55 spectrum is dominated by the $\mathrm{C} 1 \mathrm{~s}(\mathrm{C}-\mathrm{H}) \rightarrow$ $\pi^{*} \mathrm{C}=\mathrm{C}$ transition at $285.1 \mathrm{eV}$. At higher energies, the spectra of all three components show weak structure, associated with $\mathrm{C}$ 1s excitation at the chain carbons to $\sigma^{*}{ }_{\mathrm{CH}}, \sigma^{*} \mathrm{CC}$, and $\sigma^{*}$ co states. ${ }^{38}$ The spectra of the pure reference materials have been converted to a mass absorption scale by matching the signal in the preedge and postedge region to the sum of tabulated atomic mass absorption coefficients ${ }^{39}$ appropriate for the chemical composition of the component. ${ }^{29}$

Quantitative component maps for 10-90\% (v/v) EDMA shell compositions are shown in Figure 3. These were derived using singular value decomposition (SVD) $29,40,41$ of images at 285.1, 288.4, and 305.1 eV for each species. These results were carefully checked for reproducibility and sensitivity to small changes in the energy and intensity scales of the reference samples. The vertical scale of these maps is in units of $\mathrm{nm} \mathrm{g} \mathrm{cm}-3$ and thus indicates apparent thickness, assuming unit density. ${ }^{29}$

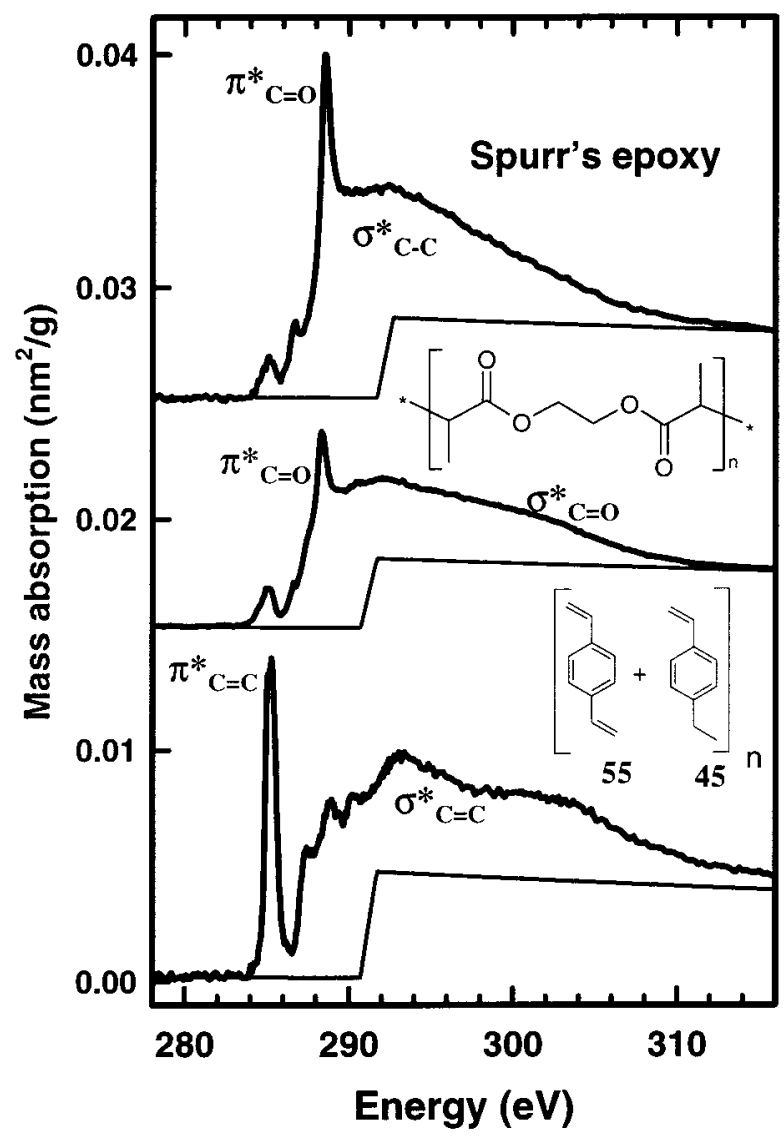

Figure 2. Spectra on quantitative mass thickness scales of the pure embedding resin (Spurr's epoxy), poly(EDMA), and poly(DVB55). The unstructured solid line is the mass absorption coefficient for the indicated compositions, determined by a stoichiometric sum of the atomic mass absorption coefficients. ${ }^{39}$ These spectra are the references used to generate composition maps.

According to these component maps, the core region of the microspheres is essentially pure poly(DVB55). The intensity of the shell region varies systematically with the changing amount of DVB55 and EDMA in the microspheres of different shell compositions. I deally, it should be possible to read off the absolute amount of DVB55 and EDMA in the shell from these component maps. However, on account of the very close similarity of their $C$ 1s spectra, the reliability of the separation of the EDMA and Spurr's resin components is not high. Thus, we have found that the most reliable way to measure the composition of the shell is to use the ratio of the amount of DVB55 in the shell to that in the core. This gives the shell composition directly, assuming the strength of the DVB55 signal in the core represents $100 \%$ DVB55. The remaining portion of the shell is assumed to be EDMA. This approach eliminates the inaccuracy of quantification coming from any possible epoxy penetration in the microspheres or the artifacts in the EDMA component map associated with incomplete separation of these components. Since the epoxy is not part of the microspheres as synthesized, it should be excluded from the shell quantitation.

The correlation of the shell composition from the STXM-based quantitation with that predicted from the synthesis is presented in Figure 4. The shell composition determined by STXM closely tracks the comonomer feed ratio. The deviation from the theoretical diagonal is largely due to the drift of the copolymer composition from the comonomer feed composition due to the un- 
DVB55
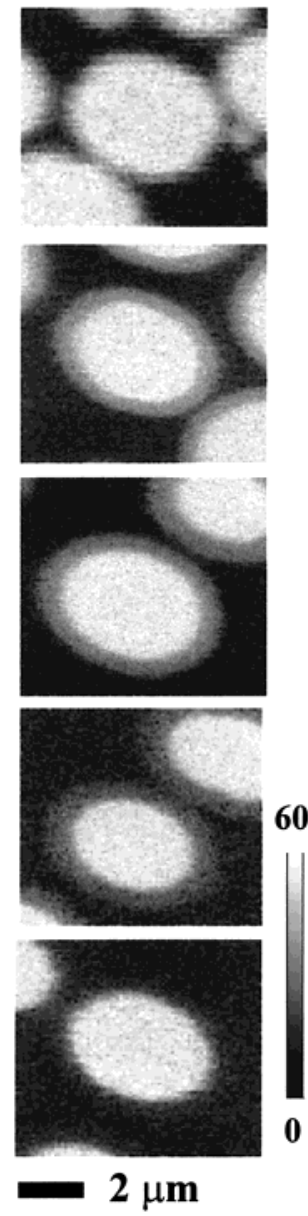

10

\section{EDMA}

30

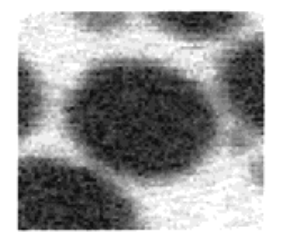

50

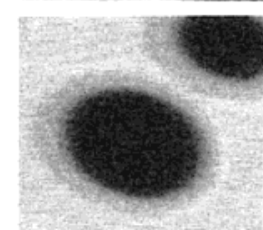

70

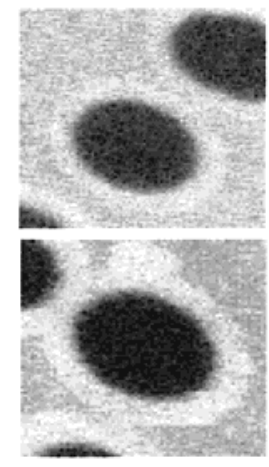

60

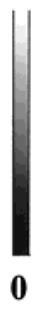

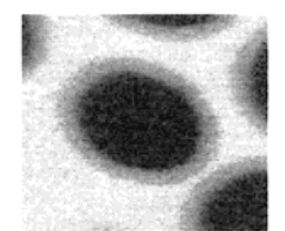

$\mathbf{v} / \mathbf{v} \%$

EDMA
Figure 3. DVB55 and EDMA composition maps for $10-90 \%$ (v/v) EDMA shell composition, derived from singular value decomposition (SVD) analysis of images at 285.1, 288.4, and $305.1 \mathrm{eV}$. In each case, the core of the particle is synthesized from $100 \%$ DVB55. The shell is synthesized using different ratios of DVB55 and EDMA, ranging from 10\% to $90 \%$ EDMA, as indicated by the numbers. This compositional variation is the origin of the changing contrast in the DVB 55 and EDMA component maps. The gray scales for the component maps are in units of $\mathrm{nm} \mathrm{g} \mathrm{cm}{ }^{-3}$ and thus indicate apparent thickness, assuming unit density.

equal reactivity of DVB55 and EDMA. ${ }^{33}$ The inset in Figure 4 illustrates this by showing the instantaneous copolymer composition calculated for the copolymerization of styrene $(r 1=0.5)$ and methyl methacrylate ( $r 2$ $=0.45$ ), two closely related monomers for which the reactivity ratios are known, over the same range of comonomer composition.

In principle, the shell-forming monomers could penetrate the partly porous core to form a composite core. Poly(DVB55) cores, due to the layer-by-layer mechanism of their growth, are expected to have a cross-linking gradient that decreases from the center to the surface, accompanied by an increasing degree of swelling in the same direction. ${ }^{36}$ The sharp boundary of the EDMA shell material suggests that there is no significant penetration of the shell-forming monomers into the core particle.

3.2. Other Information from STXM Results. For porous microspheres, one expects some penetration of the epoxy into the shell and/or core. In such cases it would be possible to estimate the porosity of the core

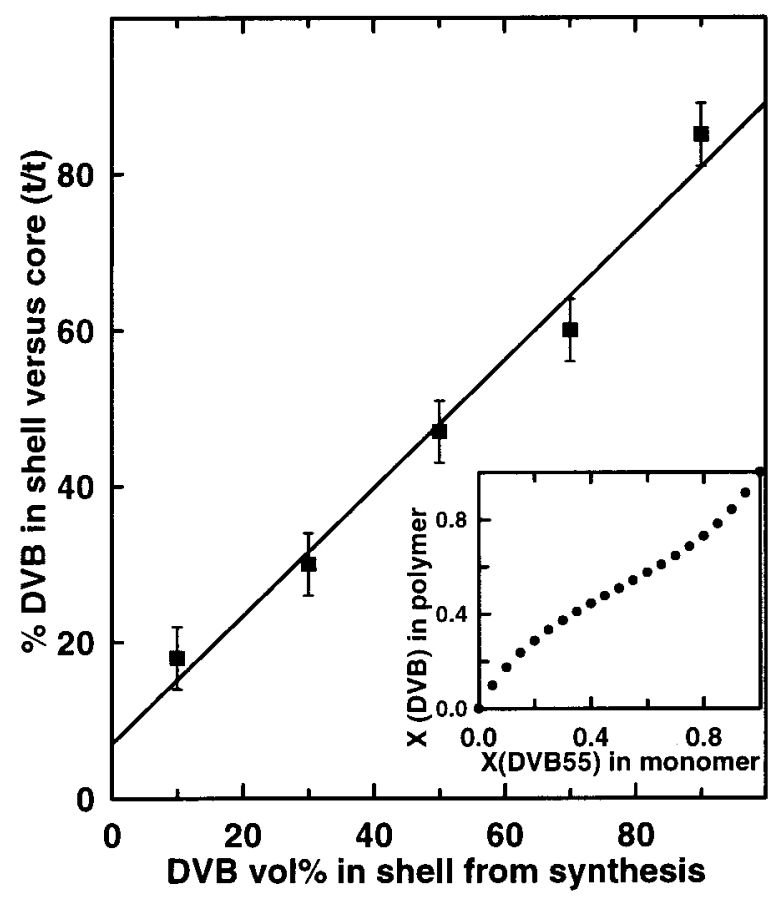

Figure 4. \% DVB in the shell relative to the core (signal/ signal), derived from the DVB composition maps, compared to the \% (v/v) DVB used in the synthetic formulation. The inset shows the instantaneous copolymer composition expected for copolymerizations of the related styrene and MMA over the same range of compositions.

and shell regions of the structure from the epoxy map. In the samples studied here, measurements of AVERAGE porosity made using BET indicate the core and shell regions are at full density and thus have no significant porosity. To be able to differentiate the epoxy from EDMA, it would be sensible to use a different epoxy, one with a significantly different $C$ is spectrum from either EDMA or DVB55. In this case, despite the unfavorable choice of epoxy, we have expl ored porosity by regression analysis of a full image sequence (200 images from 287 to $320 \mathrm{eV}$ ) of a mi crosphere sample in which the shell was 100\% EDMA. The compositional maps of all three components are shown in Figure 5. Vertical scales indicating the apparent thickness are given. In addition, intensity profiles across the microsphere are plotted. While there is evidence of mixing of epoxy and EDMA signals in the epoxy matrix, both signals are very low in the core region, consistent with the absence of porosity in this sample.

The data shown in Figure 4 are based on images obtained at only three $\mathrm{X}$-ray energies, and yet a good quantitative result was obtained. I ncreasing the number of energies used in the analysis reduces the statistical uncertainty. In general, the accuracy of any given multiimage analysis is related to the degree of differentiation of the spectral signatures of the individual components. Of course, it is essential that the reference material correspond to the actual material studied. The number of images needed for reliable quantification depends on how unique the component spectra are. The energies for the images should be selected carefully to obtain best chemical separation, while holding the number of images as low as possible to minimize radiation damage. If the spectral signature of each component is distinct, a number of images the same or just a bit larger than the number of components are sufficient for good results. It is more difficult to separate 

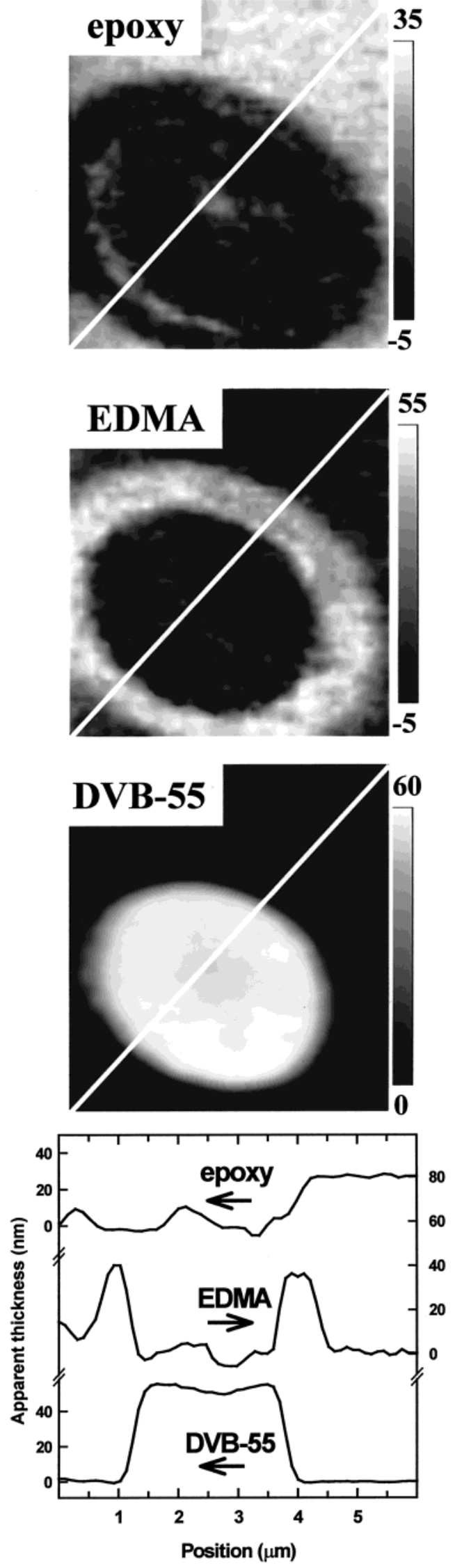

Figure 5. Maps of the epoxy, DVB55, and EDMA components derived by regression analysis of a 200-image sequence recorded from a microsphere with $100 \%(\mathrm{v} / \mathrm{v})$ EDMA shell composition. The gray scales indicate apparent thickness in nanometers (this is thickness times density). The plot is the apparent thickness along the indicated line of each component. spectrally similar components, but even in this case images at 5-10 carefully sel ected energies are sufficient. In the case of radiation-sensitive materials, the optimum strategy is to strike a balance between a larger number of energies which allow better separation of similar components against the damage caused by exposure to obtain this number of images.

The spatial accuracy of the quantification is currently limited by the accuracy of the image alignment required to correct for mechanical limitations of the current microscope. This may be part of the origin of the "shadow" signal observed on the left side of the coreshell boundary in the epoxy map shown in Figure 5, although some penetration by epoxy into this region is also possible. I nstrumental developments to reduce and possibly eliminate this factor are in progress. Ultimately, the type of quantitation illustrated here should be achievable at the spatial resolution of the microscope, which is determined by the diffraction limit of the zone plate. Recently, zone plates with $25 \mathrm{~nm}$ spatial resolution have been produced. 42

\section{Summary}

Soft X-ray microscopy images recorded at multiple wavelengths have been used to quantify chemical composition in 400-900 $\mathrm{nm}$ shells around $3.2 \mu \mathrm{m}$ diameter polymer microspheres. Quantitation at the few percent level was achieved. Optimum strategies of data acquisition and analysis were discussed. These results indicate that STXM can provide reliable chemical spe ciation at sub-100 nm spatial resolution of majority components (>5\%). This capability is being used for mapping cross-linking in fully hydrated, core-shell acrylic acid gel beads ${ }^{43}$ as well as studies of phase segregation in high-water polyurethanes, ${ }^{44}$ morphology and interface chemistry of blends, ${ }^{45}$ and investigations of strategies for control of chemical gradients in polyurea capsule walls. ${ }^{46}$

Acknowledgment. Research is funded by NSERC (Canada). We thank Tony Warwick and George Meigs for their extremely competent assistance and Harald Ade for generously donating some beam time to this experiment. We also thank Dr. Chris J acobsen (SUNY Stony Brook) for sharing his image sequence analysis software. The ALS STXM was devel oped by T. Warwick (ALS), B. P. Tonner, and collaborators. The Advanced Light Source is supported by the U.S. Department of Energy under Contract DE-AC03-76SF00098. Zone plates at ALS were provided by Eric Anderson of CXRO, LBNL.

\section{References and Notes}

(1) Vorflusev, V.; Kumar, S. Macromolecules 1999, 32, 19031905.

(2) Bonnet, A.; Pascault, J . P.; Sautereau, H.; Taha, M. Macromolecules 1999, 32, 8517-8523.

(3) Hsu, C. P.; Lee, J. Polymer 1993, 34, 4496-4505.

(4) Li, W.-H.; Hamielec, A. E.; Stöver, H. D. H. J . Polym. Sci., Part A: Polym. Chem. 1994, 32, 2029-2038.

(5) Ma, G. H.; Fukutomi, T.; Nozaki, S. J . Appl. Polym. Sci. 1997, 47, $1243-1253$.

(6) Okubo, M.; Nakagawa, T. Colloid Polym. Sci. 1994, 272, 530 535.

(7) McDonald, C. J .; Bouck, K. J .; Chaput, A. B.; Stevens, C. J . Macromolecules 2000, 33, 1593-1605.

(8) Arshady, R. Polym. Eng. Sci. 1990, 30, 905-914.

(9) Scher, H. B.; Rodson, M. US patent 5160529, issued Nov 3rd, 1992. 
(10) Wang, Q. C.; Svec, F.; Frechet, J . M. J . J . Polym. Sci., Part A: Polym. Chem. 1994, 32, 2577-2588.

(11) Li, W. H.; Stöver, H. D. H. Macromol ecules 2000, 33, 43544360.

(12) Gauthier, M.; Tichagawa, L.; Downey, J . S.; Gao, S. Macromolecules 1996, 29, 519-527.

(13) Shchori, E.; O'Driscoll, K. Polymer 1978, 19, 1074-1078.

(14) Heinrich, R.; Frensch, H.; Albrecht, K. US Patent 4409201 (Hoechst AG), 1983.

(15) Yadav, S. K.; Khilar, K. C.; Suresh, A. K. AlChE J . 1996 $42,2616-2626$

(16) Peters, E. C.; Svec, F.; Frechet, J . M. J .; Viklund, C.; I rgum, K. Macromol ecules 1999, 32,6377-6379.

(17) Egerton, R. E.; Crozier, P. A.; Rice, P. Ultrami croscopy 1987, 23, 305-312.

(18) Kumar S. Adams, W. W. Polymer 1990, 31, 15-19.

(19) Payne, R. S.; Beamson, G. Polymer 1993, 34, 1637-1643.

(20) Ade, H.; Zhang, X.; Cameron, S.; Costello, C.; Kirz, J .; Williams, S. Science 1992, 258, 972-975

(21) Ade, H.; Hsiao, B. Science 1992, 262, 1427-1429.

(22) Ade, H.; Smith, A.; Cameron, S.; Cieslinski, R.; Mitchell, G. E.; Hsiao, B.; Rightor, E. G. Polymer 1995, 36, 1843-1848.

(23) Smith, A. P.; Ade, H. Appl. Phys. Lett. 1996, 69, 3833-3835.

(24) Ade, H. Exp. Methods Phys. Sci. 1998, 32, 225-261.

(25) Warwick, T.; Padmore, H.; Ade, H.; Hitchcock, A. P.; Rightor E. G.; Tonner, B. J . Electron Spectrosc. 1997, 84, 85-98.

(26) Warwick, T.; Franck, K.; Kortwight, ]. B.; Meigs, G.; Moronne, M.; Myneni, S.; Rotenberg, E.; Seal, S.; Steele, W. F.; Ade, H.; Garcia, A.; Cerasari, S.; Denlinger, J .; Hayakawa, S.; Hitchcock, A. P.; Tyliszczak, T.; Rightor, E. G.; Shin, H.J .; Tonner, B. Rev. Sci. Instrum. 1998, 69, 2964-2973.

(27) Ade, H.; Smith, A. P.; Zhang, H.; Winn, B.; Kirz, J .; Rightor E. G.; Hitchcock, A. P. J . Electron Spectrosc. 1997, 84, 5372.

(28) Stöhr, J . NEXAFS Spectroscopy; Springer-Verlag: Berlin, 1992.

(29) Koprinarov, I.; Hitchcock, A. P.; McCrory, C.; Childs, R. F. . Phys. Chem. B, in press.

(30) Rightor, E. G.; Hitchcock, A. P.; Ade, H.; Leapman, R. D.; Urquhart, S. G. Smith, A. P.; Mitchell, G. E.; Fischer, D. A.;
Shin, H. J .; Warwick, T. J . Phys. Chem. B 1997, 101, 19501961.

(31) Okubo, M.; Ichikawa, K.; Tsujihiro, M.; He, Y. Colloid Polym. Sci. 1990, 268, 291-296.

(32) Ottewill, R. H.; Schofield, A. B.; Waters, J . A.; Williams, N. S. J . Colloid Polym. Sci. 1997, 275, 274-283.

(33) Polymer Handbook, 4th ed.; Brandrup, J ., Immergut, E. H., Grulke, E. A., Eds.; J ohn Wiley \& Sons: New York, 1999.

(34) Li, W. H.; Stöver, H. D. H. J . Polym. Sci., Part A: Polym. Chem. 1998, 36, 1543-1551.

(35) Li, W. H.; Stöver, H. D. H. J . Polym. Sci., Part A: Polym. Chem. 1999, 37, 2899-2907.

(36) Downey, J .; Frank, R.; Li, W.-H.; Stöver, H. D. H. Macromolecules 1999, 32, 2838-2844.

(37) J acobsen, C.; Wirick, S.; Flynn, G.; Zimba, C. J . Microsc. 2000, 197, 173-184.

(38) Hitchcock, A. P.; I shii, I. J . Electron Spectrosc. 1987, 42, 1126.

(39) Henke, B. L.; Gullikson, E. M.; Davis, J. C. At. Nucl. Data Tables 1993, 54, 181-342.

(40) Press, W. H. Numerical Recipes in C: The Art of Scientific Computing; Cambridge University Press: Cambridge, 1992.

(41) Zhang, X.; Balhorn, R.; Mazrimas, J .; Kirz, J . J . Struct. Biol 1996, 116, 335-339.

(42) Peuker, M. AIP Conf. Proc. 2000, 507, 682-687.

(43) Mitchell, G. E.; Wilson, L. R.; Dineen, M. T.; Urquhart, S. G.; Hayes, F.; Rightor, E. G.; Hitchcock, A. P.; Ade, H. Macromolecules, in press.

(44) Rightor, E. G.; Urquhart, S. G.; Hitchcock, A. P.; Ade, H.; Smith, A. P.; Mitchell, G. E.; Priester, R. D.; Lidy, W. Macromolecules, in press.

(45) Morin, C.; I keura-Sekiguchi, H.; Tyliszczak, T'; Cornelius, R.; Brash, J. L.; Hitchcock, A. P.; Scholl, A.; Nolting, F.; Appel, G.; Winesett, A. D.; Kaznacheyev, K.; Ade, H. J . Electron Spectrosc. Relat. Phenom., in press.

(46) Croll, L. M.; Koprinarov, I.; Hitchcock, A. P.; Li, W. H.; Stöver, H. Manuscript in preparation.

MA001626C 